\title{
Space Governance of Identity in The Aunt's Postmodern Life
}

\author{
Dongshan Sun \\ Harbin Normal University \\ Harbin, China 150025
}

\author{
Hong Zhu \\ Liaoning Normal University \\ Dalian, China 116000
}

\begin{abstract}
The Aunt's postmodern life" tells the story of the lack of identity of "aunt", it analyzes the living space and identity of floating population exist the blur of geographical space, the compression of living space and the hovering of historical space these three problems. Constructs the space governance system from the perspective of identity according to the living space and identity of floating population exist the blur of geographical space, the compression of living space and the hovering of historical space these three problems. Urban construction of space management system requires multisector collaborative governance. Multisector collaborative governance is the means of urban space governance, the methodology of urban space governance, and also a good way of urban space governance.
\end{abstract}

Keywords—identity, space governance, historical space

\section{INTRODUCTION}

"The Aunt's postmodern life" expends mainly around the daily life of the nonentity aunt. There are five main types of plot: the relationship between the aunt and her nephew, the relationship between the aunt and her daughter, the relationship between the aunt and her neighbor Mrs. Shui, the romantic relationship between the aunt and Pan Zhichang, and the plot of the nonentity aunt to help others. "The Aunt's postmodern life" ostensibly only tells the story of the nonentity aunt's daily life, but in fact when you deeply understand this film, you will find it is quite connotative. The film also inspires people's deep thinking while bringing laugh to people.

\section{THE IDENTIT Y OF "AUNT"}

The nonentity aunt in "The Aunt's Postmodern Life" has a certain representation, representing a historical figure in a period of time. Besides the artistic qualities, the film triggers people's thinking about issues like real life and historical environment. The film seems to be just about a few paragraphs of aunt's daily life, seemingly arbitrary in the structure, the story also appears to be loose, but in fact it scrambled in appearance but united in spirit, there is a central figure throughout the story, and the aunt's lovely and noble character it even more comprehensive through the whole film. For example: the plot of Aunt and her nephew is through the nephew Kuankuan's perspective to render aunt's role from side ways. Although her aunt is an affected, aloof and stingy figure in the eyes of her nephew Kuankuan, from this perspective also explores the vitality of the aunt character. From the perspective of others, the surreal vitality of auntie is given to the small potato, which makes the film "The Aunt's Postmodernism" more colorful and full of vitality. The film "The Aunt's Postmodern Life" is always with a cheerful music and a bright rhythm. The nonentity aunt in the film, whether it is to help migrant workers, or the romantic disputes with Pan Zhichang, are all interpret bitters weet stories like beautiful musical scenes.

In the film the gigantic moon comes in through the window, and the moon should represent perfect and beauty, but the meaning of the moon is exactly the opposite of the story in the film. The moon that represents the perfect and good wishes formed a sharp contrast with the aunt's numb and helpless face. The strong drop and unpleasant reality strongly slaps on her face and makes aunt's hair turn white overnight and enter the hospital. "The Aunt's postmodern life" does not have aunt crying scenes, but it interprets the helpless and numb of the aunt into perfection. The deepest sadness is not crying, but is the numbness deeply in the soul and the unspeakable helplessness. The unpleasant, bittersweet reality make the nonentity aunt can not accept. Both the big and small people have a beautiful vision of life, the moon represents a successful and beautiful vision, unfortunately the beautiful life has passed and the moon will finally become the moon in the water.

Through the appearance of aunt's daughter in the film, the story of aunt's past is brought to the audience. Aunt is a college student but married to her worker husband in the context of a big era. Aunt's pride of her own identity as well as the disdain for the rude husband gathered together is not reconciled. So when she is able to return to Shanghai, she left her husband, left her daughter and go back to Shanghai's fancy world with a leather suitcase. This seems to make a closure with the past, she is still a college student with high school diploma. But fantasies are after all fantasies, and there's always a day to wake up. The cruel reality easily tear open aunt's imaginary world, and expose the real world.

In the film "The Aunt's postmodern life", the confusion and frustration which nonentity aunt encountered in real life also revealed the lack of self-awareness of nonentity in real life. The contrast between the exaggerated fantasy and the reality made the human beings lose themselves and thus led to the individual reality dislocation. The reason why the nonentity aunt faces the reality dislocation is mainly the 
"identity". "Identity" is one of the key contents of cultural studies in recent years. From the philosophical point of view to study "identity", is the problem recognition of id. "Who am I?", "What is me?", "What represents me?" These questions all can be said as the self-identity recognition of id. "Identity" is a sign of the distinction between groups and individuals, and it is the root to distinguish the selfawareness and group consciousness. From an abstract perspective to understand "the study of self-awareness has evolved from the cave image of Plato to Freud's Lacanian image, to Lacan's mirror images, all of which are proving that ego can not verify himself, in every stage of man, whether it is childhood or adolescence, they always want to establish a stable sense of identity "[1]. And "an individual who possesses reasonably stable self-identity will feel the continuity of his personal experience that can be thoughtfully mastered and communicate with others in a certain sense" [2]. "Identity" is not an absolute concept, it is a relative concept. In fact, the urgency and anxiety of "identity" are "precisely based on the inherent unity of identity and the destruction of stability [3]. In "The Aunt's Postmodern Life", the nonentity aunt faces the "identity" problem. Although she paid a high price, but did not get "identity". The identity of aunt in the film is always in a free state, aunt's narrow living space and dazzling Shanghai has formed a stark contrast.

\section{THE LIVING SPACE AND IDENTITY OF THE FLOATING POPULATION}

In "The Aunt's Postmodern Life", the image of nonentity aunt not only reflects the problem of identity, but also reflects the lack of understanding of one's own culture and identities of the same person with aunt nowadays. The film makes up the tragedy life of nonentity aunt based on six factors, which are historical factors, environmental factors, class factors, cultural factors, urban and rural factors and social factors. Aunt is a microcosm of these six factors, she is both from Shanghai, and not from Shanghai, she is more like a stranger than strangers. Because she does not have a root, so she can only drift around and swing with the wind. She is like a wild dog wandering around looking for her home, her home is everywhere and her home is nowhere. The famous English theoretician John Tomlinson said: "For those people who have experienced migrations and transfers, "homeland "is no longer where they are now but where their emotions are rooted". In "The Aunt's postmodern life " the nonentity aunt has a certain deviation for the positioning of "Home", "home "is the harbor which carrying culture, sustenance emotion and ease anxiety. The floating population's living space and identity have the problems of three aspects: the blur of geographical space, the compression of living space and the hovering of historical space.

\section{A. The Blur of Geographical Space}

Once talked about the word "hometown", many homesickness or beautiful memories will present in our minds. Hometown is not only a matter of homesickness and good memories of human beings, but also a place where human beings can maintain their identities. When strangers meet each other, the most frequently question is "Where are you from?" and "Where is your hometown?" The fixed location seems to be the familiar basis for strangers and indirectly established the connection between people. This method is the process to determine "us" through different regions. However, the film blurred the geographical location. Although Aunt is a native of Shanghai, there is also a clear landmark of the city of Shanghai in the film, but without language, it is not easy to confirm the geographical space. Throughout the film, the most prominent landmark in Shanghai, Oriental Pearl Tower appeared when Aunt left Shanghai, which highlights the blurring of the geographical location in the film. The big city Shanghai is no different from other cities to Aunt, just like Tomlinson said, the current location is not a "home" in nature. She walked in these cities but did not deliver her emotions nor did she form the identity with them.

\section{B. The Compression of Living Space}

Familiar environment will always make people comfortable, and unfamiliar environment will always bring pressures to people. Human lived in a familiar environment, no need to adapt to the surrounding, everything is so comfortable. After change the living space, unfamiliar environment often brings confusion to the issue of human identity. Adapt to unfamiliar environment is not easy, the change of living space and the difference of language and culture make human beings become hedgehog and contradict to changes. The contrast between this inherent mode and real life, led to a subconscious resistance. The Aunt in the film is exactly lived in this life state, she has an inherent life style, her active area is limited to park, food market, nursing home and street vendors. Aunt's living space is narrow and crowded, she lived in Shanghai but she is incompatible with Shanghai. Aunt has been derailed with the modern, her English pronunciation is standard British, but the popular is American English. The aunt in the film has always been in a derailed life, living in an illusion of Shanghai and maintaining its inherent life mode, which reflect the inapplicability of the change of living space. Derailment from the times must be abandoned by the times.

\section{The Hovering of Historical Space}

Under the background of the great era, the impact of the change of state politics on the living space of human beings is enormous. It can be said that the impact of changes in historical space on human beings is more intense than that of geographical and living space. The description of the historical space in the film "The Aunt's Postmodern Life" abandoned the political factors in the country and blurred the historical space. And National politics was the root cause of the impact on human life and identity at the time of the 1980s. The weakened background in the film is also the protagonist's needs. The role of female and nonentity aunt in the film is somewhat embarrassed under the national political pattern. Denying political overtones can highlight the independent character of the aunt's role, and even remove the political factors of aunt's return to Shanghai, completely isolated Aunt from politics, so that the nonentity aunt 
became the figure who is headed to extreme in the historical torrent.

\section{BUILD A SPACE GOVERNANCE SYST EM FROM THE PERSPECTIVE OF IDENTIT Y}

In "The Aunt's Postmodern Life", the identity of the nonentity aunt has the obvious duality, and the vague awareness of class identity and the clear understanding of gender identity are mixed together. This significant duality of identities chasing its roots is the result of census register system under state policy. In philosophical terms, identity is a three-dimensional problem, first is the self-awareness of id which sum up is the question of "who am I?" Second is the understanding of id on "Qi" which is the problem of "where do I come from?" Finally, is the understanding of id on the "Shi" which is the problem of "where do I go?" These three is sues are the focus of human identity, and also contain the recognition of class identity. Marx once made an analysis of the meaning of class identity, and he believed there are two main class identities, which are class-in-itself and class-foritself. Among them, the class-in-itself is the product of capitalism, mainly referring to the role of laborers in capitalis $m$. The roles of class-for-itself laborers have clearly changed. They have awareness for their own class and they understand their own historic mission. Even in China's socialist country, class consciousness still exists. The nonentity aunt in the film has such class consciousness, she considered herself as "Shanghai people", with a strong sense of superiority. The reason for this sense of superiority is the country's census register system, which not only determines a person's place of residence, but also determines a person's social identity, such as housing, benefits, work place and so on. In China today, a man's occupation does not determine the personal status, a person's status are related with other factor, and other factors mainly refer to a person's census register. Thus, the nonentity aunt in the film is regarded as "class-for-itself" under Marx's class identity theory. She knew very well about the superiority of her census registration in Shanghai. In the film, the nonentity Aunt also has an "intellectual" identity apart from her census registration in Shanghai. This identity also gives her certain superiority. A highly educated intellectual and a rude worker have a clear disparity in class which created more of her own superiority. However, society is developing and cities are making progress. Under the wave of reform and opening up, social values have become diversified and "urban census register" is no longer important. The sense of superiority of the nonentity aunt in the film ceases to exist, which is why the aunt's class identity is blur.

The film "The Aunt's postmodern life" reflects the issue of identity recognition, which triggered people's deep thinking. China's economy is booming and the urban population is also rapidly increasing. Every year, there are tens of millions of floating population influx in Beijing, Shanghai and Guangzhou, dramatic changes have taken place in urban space, and the life of urban residents has also been affected by the foreign population. This effect directly leads to the confusion about their identity, and even stubbornly rejects change. Therefore, in order to maintain a stable and orderly urban space to ensure long-term peace and stability in the city, the city should establish a space governance system.

The City should establish a space governance system that is a complex systematic engineering project, involving multiple subjects and departments. To manage the urban public space can promote the good cooperation among urban main bodies and provide the urban residents with an excellent space environment, and also provide a solid theoretical foundation and practical opportunity for the urban public space governance system. The construction of space governance system requires multi-sector collaborative governance. Multi-sector collaborative governance is the means of urban space governance, the methodology of urban space governance, and also a good way of urban space governance. First of all, multi-sector collaborative governance is the ideal solution to the problem of urban space governance. Today's society is a group society, group collaboration is fundamental. China has always called for the spirit of group cooperation in policy, giving full play to the public's strength, attaching importance to public participation, paying attention to the spirit of social cooperation and letting government work closely with the society. To solve the problem of urban space governance is to give play to the power of society so that policies and social integration will be closely linked. Second, multi-sector collaborative governance is a methodology to solve urban spatial governance problems. With the increase of urban floating population and the shortage of urban public space resources, how to solve the shortage of urban space resources has become a barrier to urban development. The city's public resources has the class nature, rich people receive more public resources while poor people only receive less public resources. All kinds of unreasonable problems of public resources in these cities need to be solved. And Multi-sector collaborative governance is an important way to remedy these gaps. Finally, multi-sector collaborative governance is a good way to achieve urban space development. The development of the city will involve the interests of many parties, people, enterprises and the government plays different roles in urban development and also emerge many conflicts. Multi-sector collaborative governance could protect people's immediate interests, also could it is convenient for the policy communication.

\section{CONCLUSION}

This article include the thinking of the film "The Aunt's Postmodern Life", the lack of identity of "aunt", it analyzes the living space and identity of floating population exist the blur of geographical space, the compression of living space and the hovering of historical space these three problems. Constructs the space governance system from the perspective of identity according to the living space and identity of floating population exist the blur of geographical space, the compression of living space and the hovering of historical space these three problems. China's economic development is inseparable from the city's participation. The establishment of a space governance system is the only way for urban public space governance and also an inevitable way for the 
rapid urban development in China. The establishment of a space governance system can promote social development, it is conducive to the planning of urban space, and it could save the cost and reduce losses.

\section{REFERENCES}

[1] Luo Huilin. Adult Perspective: Cultural Paradoxes with Identity Anxiety: A Case Study of Zhang Ailing's Early Creation [J] .New Theory of Tianfu, 2006, (1) p143.

[2] Anthony Giddens. Modernity and self-identity [M]. Translated by Zhao Xudong, Fang Wen. Beijing: SDX Joint Publishing Company, 1998: p60.

[3] Qian Chaorong. Identity Concept and Identity Consciousness [J]. Journal of Shenzhen University: Humanities and Social Sciences, 2000,17 (2): p91. 